\title{
PHYSICAL AND MECHANICAL PROPERTIES OF THREE POLYSTYRENE IMPREGNATED INDONESIAN WOOD SPECIES
}

\author{
Nurwati Hadjib ${ }^{1}$
}

\begin{abstract}
The disadvantage of fast-growing species is that they have inferior physical and mechanical properties. Polystyrene impregnation can be applied to improve physical and mechanical properties. Wood samples, which were dried until $10 \%$ moisture content were put into impregnating tank and vacuum pressured at $20-\mathrm{mm} \mathrm{Hg}$ for two hours. During the gradual release of vacuum, styrene monomers, vinyl acetate monomers and terbutyl-peroxide catalyst was streamed into the tank. Afterwards, the pressure inside the tank was allowed to decrease to $500 \mathrm{~mm} \mathrm{Hg}$ and kept for 60 minutes. Wood samples which had been impregnated were subsequently immersed in water, then wrapped in aluminum foils and put in the oven for 24 hours at $60^{\circ} \mathrm{C}$. The samples were then tested for the polymer loading and their physical and mechanical properties. The results showed that the polymer loadings in wood plastics with the species of origin (i.e. consecutively sengon, pine and rubber wood) were $118 \%$, $72 \%$ and $44 \%$, respectively. Impregnation with polystyrene (copolymer of styrene and vinyl acetate monomers) could improve the physical and mechanical properties of wood plastics, i.e. specific gravity, moisture content, water absorption, shrinkage/swelling, compression parallel to the wood grain, MOR and MOE. Greater use of vinyl acetate decreased physical and mechanical properties.
\end{abstract}

Keywords : wood species, vinyl acetate, styrene monomers, polystyrene copolymer, wood plastic

\section{INTRODUCTION}

Wood has long been recognized by the community, as the multi-purpose materials. In this regard, wood materials can be utilized for either construction, decoration, source of energy, weapons, or other uses. Wood, as multi-purpose materials and considering its essential existence, in its development has underwent a lot of modification. This fact is also spurred by some accompanying inconvenient situations, e.g. more difficulty in procuring wood, the ever-increasing price of solid wood products, and less available timber with adequate strength and high durability; and even by the demand of creating appropriate technology applicable to a more efficient wood utilization (Hadjib and Abdurachman, 1999).

Since then, certain people or related parties have made a great stride in adopting proper technologies to convert wood such that its properties can be suited with the needs of the people/parties referred to. Among them is the technology of manufacturing wood polymer composite (WPC) so-called more famously as wood plastic. Wood plastic has some benefits, among which are its rigidity and high strength, thereby rendering it suitable for its heavy-duty uses under harsh circumstances. Besides, this plastic technology can also transform wood of rather soft/weak texture as well as low durability into a hard, rigid, durable, dimensionally more stable, and stronger material (Hadjib and Sumarni, 2000).

\footnotetext{
${ }^{1}$ Forest Products Rèsearch and Development Center, Bogor
} 
The manufacture of wood plastic can be performed in principle by at first impregnating certain monomers into wood structure, assisted under vacuum system, then followed by polymerization (curing) of the monomers using heat or radiation. Both heat and radiation methods have their own advantages or weakness. Polymerization with radiation will take shorter duration; and also, the possibility of air pollution intensity as incurred is much smaller than with heating method. However, the draw-back with radiation is requiring high initial investment cost. Conversely, polymerization by heating, besides its low-cost expenses, does not require a high-level technology. The disadvantages nevertheless are among others its high risks of air pollution and the necessity of using certain catalysts, which can be toxic and environmentally harmful (Hadi et al., 1998).

Considering the a fore mentioned situations as such and taking into account the recent gloomy economic situation faced by the Indonesian state plus with the ever-increasing wood demand, investigation on the manufacture of wood plastic has been accomplished. In this regard, this report deals with a resulting trial on wood plastic manufacture from certain Indonesian wood species. The wood species selected for this trial were those of fast-growing trees and used numerously in the establishment of plantation forest (timber estate). Further, the monomers as impregnated into wood structure were styrene and vinyl acetate, and then both polymerized by heat curing.

\section{MATERIALS AND METHODS}

\section{A. Materials}

Wood species used in this trial were, i.e. tusam (Pinus merkusii Jung. et. de Vries), rubberwood (Hevea brasiliensis Muell. Arg.), and sengon (Paraserianthes falcataria (L.) Nielsen). The main chemicals were styrene and vinyl acetate monomers, while the chemical catalyst was terbutyl-peroxyde. Other auxiliary matters were tissue paper and aluminium foil.

\section{B. Methods}

1. Preparation of wood piece samples to be tested

Samples of rubber wood, tusam, and sengon wood pieces were each made into specimens with $30-\mathrm{mm}$ thick by $30-\mathrm{mm}$ width by $400-\mathrm{mm}$ length. The specimens were further cut to smaller pieces, separated, and then allocated for the testings on their disk and mechanical properties, as follows:

- 30- $\mathrm{mm}$ by $30-\mathrm{mm}$ by $25-\mathrm{mm}$ pieces for physical properties

- 30 - $\mathrm{mm}$ by $20-\mathrm{mm}$ by $350-\mathrm{mm}$ pieces for static bending tests

$-30-\mathrm{mm}$ by $20-\mathrm{mm}$ by $80-\mathrm{mm}$ pieces for compression parallel to the grain tests

- 30- $\mathrm{mm}$ by $30-\mathrm{mm}$ by $10-\mathrm{mm}$ pieces for hardness tests

The treatment implemented on samples impregnated with plastic monomers (i.e. styrene and vinyl acetate) plus terbutyl-peroxide as catalyst, and the polymerization of both monomers conducted by heat curing. The mixture between styrene and vinyl acetate monomers was made into 4 various respective proportions, i.e. (0.6:0.4), (0.7:0.3), (0.8:0.2), and $(0.9: 0.1)$. The catalyst of terbutyl-hydroperoxide was used at $0.25 \%$ based on the weight 
of the solution containing the mixture of styrene and vinyl acetate monomers. Number of samples to be impregnated with styrene-vinyl acetate monomers at each of the four mixed proportions were 4 wood pieces, which were further regarded as 4 replicates.

Prior to the impregnation, samples of wood pieces were each dried to air-dry condition at approximate temperature of $70^{\circ} \mathrm{C}$ for 24 hours, and then their dimension and weight were measured. Wood pieces were further put into the impregnating chamber where vacuum condition at $500 \mathrm{~mm} \mathrm{Hg}$ was held for 60 minutes, followed by effecting the pressure at 1 atmosphere for 60 minutes, thereby in all forcing the solution containing both styrene and vinyl acetate monomers (plus terbutyl-peroxide catalyst) into the chamber. Afterwards, final vacuum at $500 \mathrm{~mm} \mathrm{Hg}$ was held for 15 minutes toward more completion of monomer impregnation, and then released.

Further, monomers-impregnated wood pieces were still kept in the chamber and let immerse in the monomer solution for 24 hours. Thereafter, the impregnated wood pieces were removed, and their surface cleaned of residual monomers which might stick to it. Samples of monomers-impregnated pieces were wrapped in aluminum foil and then heated at $60^{\circ} \mathrm{C}$ for 15 minutes, enabling the polymerization (curing) of both monomers to occur and then converting the pieces into wood plastic. After heating, pieces of the wood plastic were each removed of their aluminum wrap, and then their weight measured to determine the "polymer loading". After this determination, the wood plastics with respect to their specific treatment (i.e. mixed proportion between styrene and vinyl acetate monomers) were each tested of their physico-mechanical properties.

\section{Testings on wood plastics}

a. Physical properties

These properties included polymer content (polymer loading), density, moisture content and shrinkage as well as swelling of wood plastics

- Polymer loading (PL) was determined using the following formula:

$$
\mathrm{PL}(\%)=100 \mathrm{x}(\mathrm{Wi}-\mathrm{Wo}) / \mathrm{Wo}
$$

where: $\mathrm{Wi}=$ weight of monomers-impregnated wood pieces before heat-induced polymerization

Wo $=$ weight of monomers-impregnated wood pieces after heat-induced polymerization

- Density (S); using formula:

$$
\mathrm{S}\left(\mathrm{g} / \mathrm{cm}^{3}\right)=\mathrm{W} / \mathrm{V}
$$

Where: $\mathrm{W}=$ weight of wood plastics $(\mathrm{g})$

$$
\mathrm{V}=\text { volume of wood plastics }\left(\mathrm{cm}^{3}\right)
$$

- Moisture content (MC): this measurement was conducted to see the moisture content of wood plastic under air dry condition. In this regard, the MC (on the dry basis) of wood piece samples was measured.

- Shrinkage (Sh) and swelling (Sw) in volume of wood plastics: determination on Sh and Sw was conducted after wood plastics were immersed in water for 24 hours. Sh in volume was measured on wood plastic samples beginning from their volume under their wet condition 
to oven-dry condition. Meanwhile, Sw in volume was determined when the volume of wood plastics was under air-dry condition until wet condition.

- Water absorption (Wabs) of wood plastics was determined, as follows:

Wabs $(\%)=100 \times(\mathrm{W} 1-\mathrm{Wo}) / \mathrm{Wo}$

where: Wo = weight of wood plastics before immersion (gram)

W1 = weight of wood plastics after immersion (gram)

b. Mechanical properties

In this regard these properties was examined using the universal testing machine (UTM). The properties tested included:

- Static bending strength; samples of wood plastics for this testing were those with span length of $28 \mathrm{~cm}$, with center-point loading. This testing would result in the values of modulus at proportional limit (MPL), modulus of elasticity (MOE) and modulus of rupture (MOR).

- Maximum compressive strength parallel to the grain.

- Hardness; this represents the resistance of wood plastic to wear and marring. In this regard, hardness was measured by the load required to imbed a steel ball of approximately 1-cm diameter to one-half its diameter in the surface of wood plastic. The load referred to the hardness of the tested wood plastic sample.

c. Data analysis

The analysis used to evaluate the resulting data from the testings on wood plastic was completely randomized block design. In this design, two factors were included, i.e. (1) four various respective mixed proportions of styrene and vinyl acetate monomers (i.e. (60:40), (70:30), (80:20), and (90:10)) as impregnated in wood pieces compared with the control (unimpregnated pieces); and (2) three different wood species (i.e. tusam, rubber-wood and sengon). Further, the replication of each treatment combination between these two factors was 4.

\section{RESULTS AND DISCUSSION}

\section{A. Physical Properties}

1. Polymer content (polymer loadings)

Average of polymer loadings in the resulting wood plastics is presented in Table 1. 
Table 1. Polymer loading $(\%)^{1)}$ in the resulting wood plastics impregnated with styrene-vinyl acetate monomers

\begin{tabular}{|l|c|c|r|r|}
\hline \multirow{2}{*}{$\begin{array}{c}\text { Wood species } \\
\text { Jenis kayu }\end{array}$} & \multicolumn{4}{|c|}{ Styrene portion (\%) } \\
\cline { 2 - 5 } & 60 & 70 & 80 & 90 \\
\hline Tusam & 41.17 & 51.28 & 96.92 & 99.69 \\
Rubber-wood & 26.87 & 41.68 & 58.88 & 50.14 \\
Sengon & 46.21 & 118.97 & 168.36 & 137.01 \\
\hline
\end{tabular}

1) Average of 4 replications

The highest polymer loading in the wood plastic was the one impregnated with styrenevinyl acetate monomers at their respective mixed proportion of 80:20. Further, different wood species at various mixed proportions of styrene-vinyl acetate monomers significantly brought about different maximum polymer loadings. The polymer loadings of wood plastics from rubber-wood were in particular the lowest compared to the other two species (Table 1 and Figure 1). The possible explanation was that rubber-wood belongs to hardwood, with porous structure in diffuse patterns, pore size smaller than that in sengon, and cell wall thicker than in sengon. These characteristics of rubber-wood render this species difficult on its impregnation by aqueous liquid (e.g. solution of styrene-vinyl acetate monomers in this case). The analysis variance (Table 2) further revealed that different mixed proportions of styrenevinyl acetate monomers brought about significant effect, whereby the lower the portion of vinyl acetate (i.e. the higher the styrene portion), the greater the polymer loadings in the wood structure (Table 1 and Figure 1). The arguable explanation was that during impregnation under high vacuum the styrene monomers moved faster than vinyl acetate monomers in filling-up the pores and other void spaces of wood structure previously occupied by water and air.

Table 2. Analysis of variance on polymer loadings

\begin{tabular}{|l|c|c|c|c|}
\hline Sources of variation & Df & Sum of squares & Mean square & F-calculated \\
\hline Wood species & 2 & 43772.96 & 21886.48 & $29.61^{* *}$ \\
\hline Treatment & 3 & 34149.79 & 11393.26 & $15.40^{* *}$ \\
\hline Error & 42 & 31039.04 & 739.02 & \\
\hline Total (corrected) & 47 & 108961.80 & & \\
\hline
\end{tabular}

Remarks : ** $=$ significant at $1 \%$ level $(\mathrm{P}=0.99)$

In addition, the implementation of vacuum-pressure system during the impregnation of monomers into wood structure also affected the polymer loadings. Vacuum system might bring about the moving out of oxygen gas previously inside the cell wall (lumens) or in other void spaces of wood structure. Otherwise, the oxygen will react with monomers to form oxide compounds, thereby to certain extent reducing the number of cross-linkings between the monomers themselves or between the monomers and particular chemical substances of wood (Mott and Rotariu, 1968). Consequently, with numerous void spaces in the wood structure, the cross-linking reactions would be more likely to occur under vacuum system compared to the one without vacuum. 


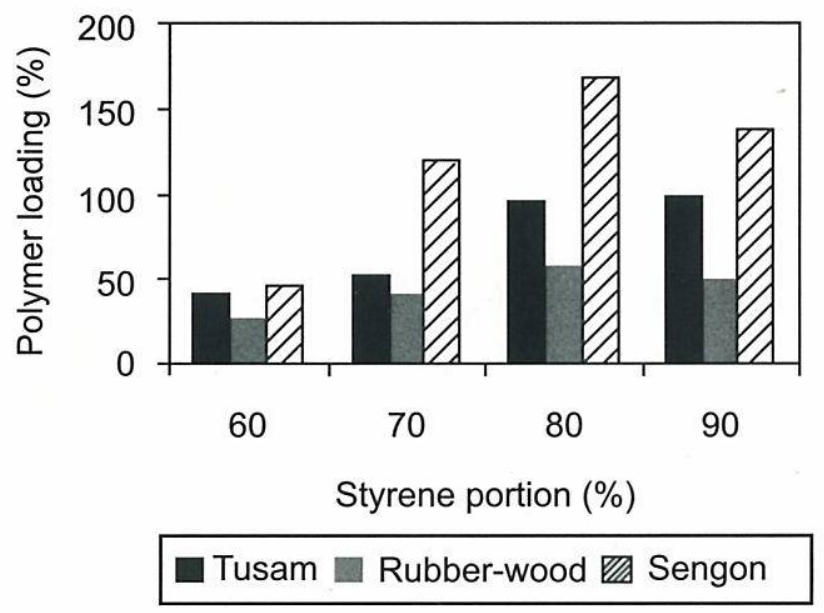

Figure 1. Polymer loadings of the resulting wood plastic at certain mixed proportion between styrene and vinyl acetate monomers

\section{Density}

Impregnation with styrene-vinyl acetate monomers at their increasing portion affected significantly and positively the specific gravity of the resulting wood plastics. This might be attributable to the ability of styrene to cross-link certain chemical substances in the wood cell wall. The polymer of styrene-vinyl acetate further filled-up the pores and other void spaces in the wood structure, thereby increasing the effective weight of the wood plastic itself. The data on average specific gravity/density of wood plastics were presented in Table 3. Further evaluation using Duncan's range tests revealed that the use of styrene at $60 \%, 70 \%, 80 \%$ and $90 \%$, brought about significant difference in density of the resulting wood plastics; and in all it was higher than the one of control (untreated wood).

Table 3. Density $\left(\mathrm{g} / \mathrm{cm}^{3}\right)^{1)}$ in the resulting wood plastics impregnated with styrene-vinyl acetate monomers

\begin{tabular}{|l|c|c|c|c|c|}
\hline \multirow{2}{*}{ Wood species } & \multicolumn{5}{|c|}{ Styrene portion (\%) } \\
\cline { 2 - 6 } & 60 & 70 & 80 & 90 & 100 \\
\hline Tusam & 0.44 & 0.69 & 0.74 & 0.97 & 1.02 \\
Rubber-wood & 0.63 & 0.78 & 0.88 & 0.91 & 0.97 \\
Sengon & 0.22 & 0.43 & 0.67 & 0.81 & 0.70 \\
\hline
\end{tabular}

1) Average of 4 replications 


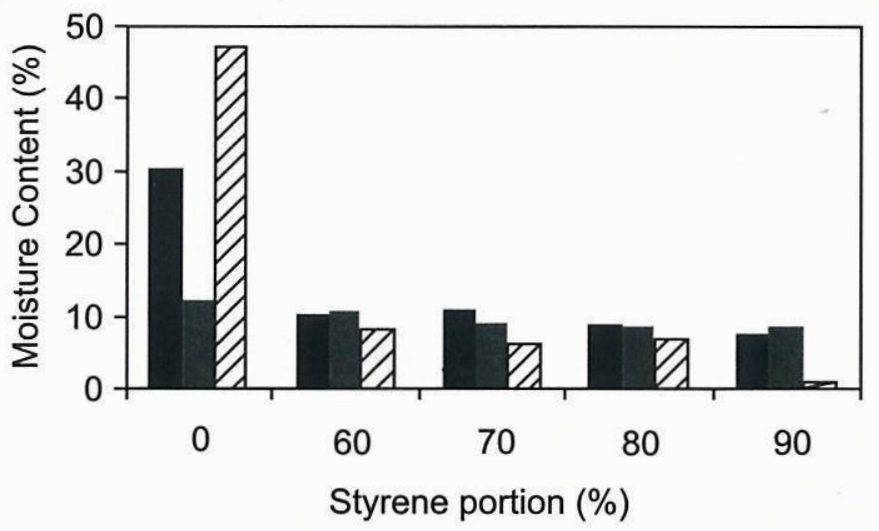

Tusam

Figure 2. Moisture content in the resulting wood plastic impregnated with certain mixed proportion of styrene and vinyl acetate monomers

Remarks : $(0)=$ Untreated wood (control)

\section{Moisture content}

Wood plastics resulting from the impregnation by styrene monomers in various portions revealed significant difference in their moisture content (Appendix 1). This is because, before the impregnation, the heating/drying of wood at $70^{\circ} \mathrm{C}$ for 24 hours had forced out certain amount of its water content occupying lumens and other spaces inside wood structure. During the impregnation, the styrene would fill-up those lumens and other void spaces in wood, replacing the water. Further, the styrene might cross-link the wood cell wall chemically, rèndering the wood unable to bond or attract water effectively and causing the decrease in its moisture content such that it was lower than that in the untreated (unimpregnated) corresponding wood (control). In addition, the moisture content tended to decrease with the increase in styrene portions (Figure 2). The data on moisture content of the resulting wood plastics were presented in Table 4.

Table 4. Average moisture content $(\%)^{1)}$ in the resulting wood plastics impregnated with styrene-vinyl acetate monomers of moisture content (\%) of wood plastic tested

\begin{tabular}{|l|c|c|c|c|c|}
\hline \multirow{2}{*}{ Wood species } & \multicolumn{5}{|c|}{ Styrene portion (\%) } \\
\cline { 2 - 6 } & 0 & 60 & 70 & 80 & 90 \\
\hline Tusam & 30.23 & 10.36 & 10.48 & 8.87 & 7.26 \\
Rubber-wood & 12.01 & 10.50 & 9.07 & 8.44 & 8.44 \\
Sengon & 46.93 & 7.90 & 6.12 & 6.55 & 6.55 \\
\hline
\end{tabular}

Remarks: $(0)=$ Untreated wood (control)

1) = Avérage of replications 
4. Volumetric shrinkage and swelling, and other related characteristics

a. Water absorption

This is related to the wood capability of water absorption. Wood with low water absorption is more preferable than the one with high water absorption. The manufacture of wood plastics with different mixed proportion of styrene and vinyl acetate brought about significant difference as well in their water absorption. The cross-linking reaction between styrene-vinyl acetate monomers and wood cells have converted the hydrophilic nature of cell wall into its hydrophobic characteristics, thereby reducing their water absorption. In this regard, the water absorption of the overall resulting wood plastics was lower than control or unpolymerized/unimpregnated wood (Figure 3 and Table 5). Further, the higher the portion of styrene monomers, the lower the water absorption of the wood plastics. This occurrence was significantly verified by the Duncan's range tests (Appendix 1).

Table 5. Water absorption (\%) in the resulting wood plastics impregnated with styrene-vinyl acetate monomers

\begin{tabular}{|l|c|c|c|r|r|}
\hline \multirow{2}{*}{ Wood species } & \multicolumn{5}{|c|}{ Styrene portion (\%) } \\
\cline { 2 - 6 } & 0 & 60 & 70 & 80 & 90 \\
\hline Tusam- & 96.66 & 48.07 & 33.94 & 13.77 & 7.86 \\
Rubber-wood & 40.35 & 20.51 & 15.10 & 13.63 & 10.88 \\
Sengon & 34.12 & 28.77 & 12.65 & 6.66 & 10.85 \\
\hline
\end{tabular}

Remarks : $(0)=$ Untreated wood (control)

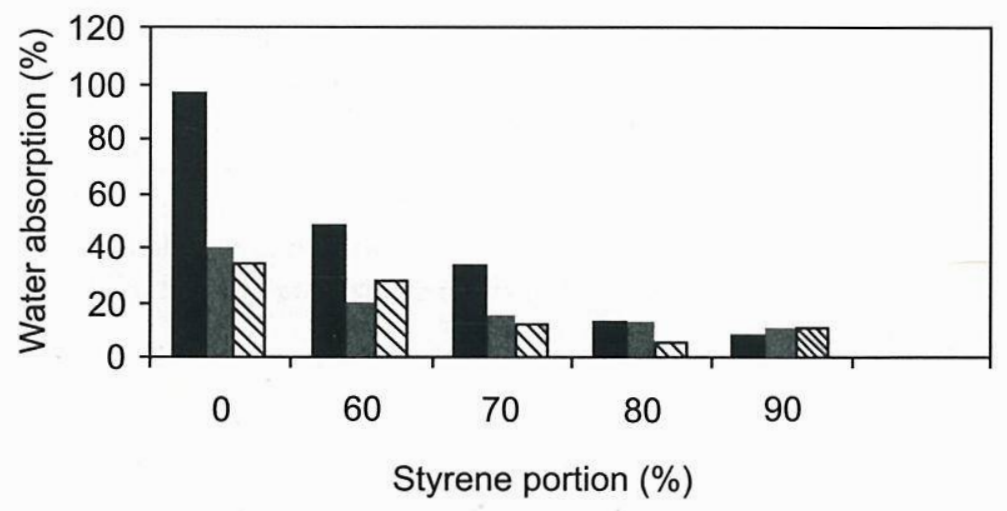

\section{Tusam}

Figure 3. Water absorption (\%) of styrene-wood-plastic tested Remarks : $(0)=$ Untreated wood (control) 
b. Volumetric shrinkage and swelling

One of other indicators to evaluate whether certain wood pieces are dimensionally stable or not is by looking into their volumetric shrinkage and swelling, in addition to their water absorption. In this regard, impregnation of three wood species (i.e. tusam, rubberwood, and sengon) each with styrene-vinyl acetate monomers brought about the decrease in their volumetric shrinkage/swelling compared to the one of unimpregnated wood or control (Table 6). Besides, the higher the mixed portion of styrene, the lower the volumetric shrinkage/swelling. This phenomenon could occur due to the impregnation of styrene-vinyl acetate monomers into wood structure, which were chemically cross-linked with wood cell wall and further the results referred to acting as a bulking agent. This agent subsequently could inhibit dimensional changes of wood (Hadjib et al., 1998).

Table 6. Volumetric shrinkage/swelling (\%) in the resulting wood plastics impregnated with styrene-vinyl acetate monomers

\begin{tabular}{|l|c|c|c|c|c|c|}
\hline \multirow{2}{*}{ Wood species } & \multirow{2}{*}{$\begin{array}{c}\text { (Shrinkage/ } \\
\text { Swelling) }\end{array}$} & \multicolumn{5}{|c|}{ Styrene portion (\%) } \\
\cline { 3 - 7 } & & 0 & 60 & 70 & 80 & 90 \\
\hline Tusami & Sh & 7.63 & 5.05 & 4.13 & 3.27 & 3.58 \\
Rubber-wood & Sw & 5.73 & 4.88 & 3.29 & 3.67 & 2.63 \\
& Sh & 7.48 & 5.27 & 5.36 & 6.17 & 6.18 \\
Sengon - & Sw & 5.46 & 3.38 & 3.21 & 3.53 & 3.93 \\
& Sh & 6.69 & 4.88 & 4.83 & 3.75 & 3.35 \\
& Sw & 4.05 & 2.97 & 3.37 & 2.19 & 2.66 \\
\hline
\end{tabular}

${ }^{1)} \mathrm{Sh}=$ shrinkage; and Sw = swelling

\section{B. Mechanical Properties}

Impregnation of wood with styrene-vinyl acetate monomers at various mixed proportions resulted in wood plastics with significantly different bending strength as well (Table 7).

Table 7. Mechanical properties of wood plastics resulting from the impregnation with various respective mixed proportion of styrene and vinyl acetate monomers

\begin{tabular}{|l|l|r|r|r|r|r|}
\hline \multirow{2}{*}{ Wood species } & \multirow{2}{*}{ Properties 1) } & \multicolumn{4}{|c|}{$\begin{array}{c}\text { Mixture proportion between respective } \\
\text { Styrene and vinyl acetate monomers }\end{array}$} \\
\cline { 3 - 7 } & & Control & $(60: 40)$ & $(70: 30)$ & \multicolumn{1}{|c|}{$(80: 20)$} & $(90: 10)$ \\
\hline Tusam & MOE & 76153 & 111005 & 172847 & 152269 & 94003 \\
& MOR & 598.09 & 1190.26 & 1253.96 & 1608.71 & 103004 \\
& Compression // & 393.32 & 561.15 & 507.51 & 484.09 & 624.10 \\
& Hardness & 286.86 & 702.30 & 545.00 & 722.81 & 570.43 \\
\hline Rubber-wood & MOE & 117912 & 142984 & 125470 & 106092 & 130541 \\
& MOR & 1060.22 & 1107.68 & 1268.68 & 1350.71 & 1545.59 \\
& Compression // & 488.93 & 483.17 & 461.11 & 486.52 & 449.61 \\
& Hardness & 471.56 & 1020.00 & 1020.63 & 942.50 & 1026.88 \\
\hline Sengon & MOE & 77945 & 62356 & 84438 & 108544 & 88629 \\
& MOR & 468.17 & 382.20 & 528.74 & 741.52 & 677.92 \\
& Compression // & 192.42 & 282.20 & 280.95 & 250.61 & .320 .26 \\
& Hardness & 147.19 & 174.38 & 158.13 & 145.00 & 454.06 \\
\hline
\end{tabular}

${ }^{1)} \mathrm{MOE}=$ modulus of elasticity $\left(\mathrm{kg} / \mathrm{cm}^{2}\right) ; \mathrm{MOR}=$ modulus of rupture $\left(\mathrm{kg} / \mathrm{cm}^{2}\right) ; \mathrm{C} / /=$ compression parallel to the grain $\left(\mathrm{kg} / \mathrm{cm}^{2}\right)$; and $\mathrm{H}=$ hardness $\left(\mathrm{kg} / \mathrm{cm}^{2}\right)$ 
Table 7 revealed that the entire bending strength of wood plastics resulting from the impregnation with styrene-vinyl acetate monomers was practically higher than that of unimpregnated wood (control). However, it turned out that the increase in portions of styrene monomers did not seem increasing the bending strength, especially MOE and MOR. The possible explanation is as follows: as it is accepted in theory, the increase in styrene portions can bring about more numerous occurrence of their cross-linking reaction with the wood cell wall. However, a critical attention should be considered that inside the wood cell are in fact existed amorphous and crystalline regions. In crystalline region, the bending forces between polymer chains brought about by this cross-linking reaction was significantly effective. However, in the amorphous region, this corresponding bending strength might not work out effectively, despite the more intense occurrence of cross-linking reaction (Cowd, 1991). This also means that in this regard the more numerous cross-linkings are not always accompanied by the higher MOE of the resulting wood plastics.

Further, Table 7 and Figure 4 showed that not all of the tested wood plastics with the highest MOR came up with the highest MOE either. This might be attributable to the crosslinking occurrences which further could assist the formation of elastomeric/tough properties (Allock and Lampe, 1981). As an example, in wood plastics from rubber-wood, the use of $60 \%$ portion of styrene turned out to have higher MOE than the one with $80 \%$ of styrene. However, for the MOR values, the reverse was true. Presumably, the amorphous regions in rubber-wood sample for the use of styrene at $80 \%$ had greater area than those at $60 \%$. Therefore, the resulting wood plastics in this regard which contained greater area of amorphous regions and more intensive cross-linkings would be more easily bent than the one which had greater crystallite regions but with less intensive cross-linkings. On the contrary, while on the verge of being bent, the amorphous regions could transform themselves to crystalline regions, thereby effecting the bending forces between polymers. As a consequence, the load which was required to rupture the wood plastics became greater than the one on those with fewer number of cross-linking.
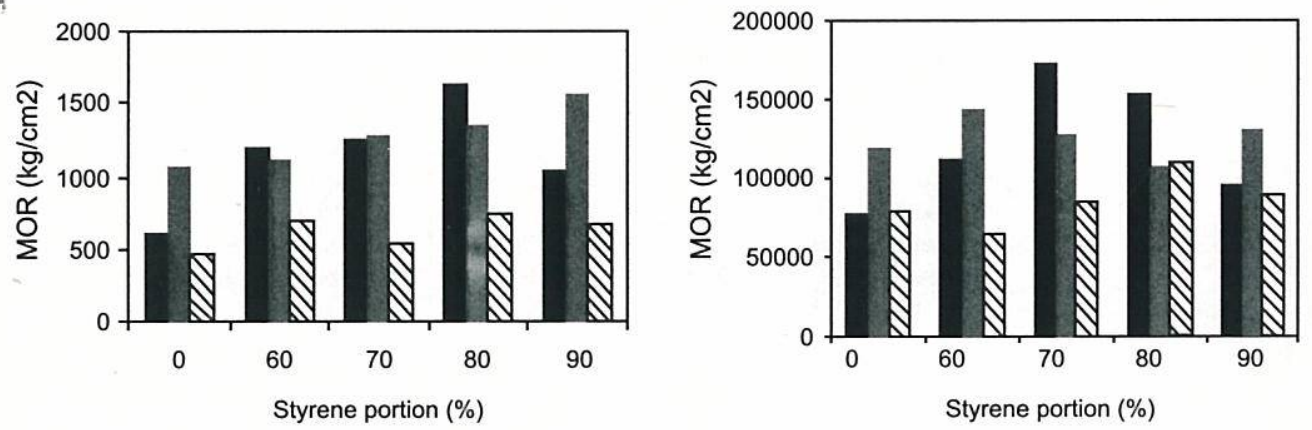

Tusam

Figure 4. MOR and MOE of wood plastics impregnated with styrene 
Table 7 also revealed that the increase in portions of styrene monomers tended to increase compression parallel to the grain and hardness of the resulting wood plastics. This phenomenon might have a strong link with the extent of polymer loadings in the wood plastics (Figure 1), which had occurred. In this regard, the greater polymer loadings brought about the higher compression strength parallel to the grain. In a particular occasion, for wood plastics from tusam and rubber-wood, it seems that mixed portion of styrene monomers at $80 \%$ appeared to be optimum. This is because at that percentage portion, the polymer loadings in the wood plastics referred to might be maximum, resulting in their highest value of compression parallel to the grain. Likewise, the increase in styrene portion beyond $80 \%$ did not make the hardness of the corresponding wood plastics any higher either, except for the one from sengon wood (Table 7). In the testings on the hardness of wood plastics, not all their side-grain portions impregnated by monomers were examined. This is because wood plastics could be damaged physically, since the characters of styrene-vinyl acetate monomers were rather brittle, thereby decreasing their hardness values. Subsequent data interpretation using Duncan's range tests revealed that the MOR of wood plastics impregnated with styrene at $70 \%, 80 \%$ and $90 \%$ portion (Figure 4 ) was significantly different from the one of unimpregnated wood (control).

Meanwhile, the Duncan's tests on compression strengths parallel to the grain of the wood plastics revealed that they were each significantly different at $60 \%$ and $90 \%$ portions of styrene impregnation. These tests also showed that overall compression strengths of wood plastics were significantly higher than those of non-impregnated wood. Further, in the respect of side-grain hardness values, those of wood plastics resulting from the impregnation with $60 \%, 70 \%, 80 \%$ and $90 \%$ of styrene portion were significantly different from each other and all significantly higher than non-impregnated wood.

\section{CONCLUSIONS AND RECOMMENDATIONS}

\section{A. Conclusions}

The conclusions which can be drawn from trial on manufacturing wood plastics through the impregnation with styrene-vinyl acetate monomers at their various respective mixed proportion are as follows:

1. In general and based on the standpoint of wood utilization, the characteristics of wood plastics from fast-growing wood species (i.e. tusam, rubber-wood, and sengon) were better than those of unimpregnated woods (control), each of the corresponding three species. However, the increase of polymer loadings in the wood cells (i.e. as brought about by increasing portion of styrene impregnation) was not always accompanied by the increase in physical and mechanical properties of the resulting wood plastics. This might be due to the unstable behavior of styrene monomers themselves inside the wood cells.

2. The use of styrene monomers at $80 \%$ portion appeared to be optimum compared to the other implemented styrene portions (i.e. $60 \%, 70 \%$ and $90 \%$ ). This is because at the $80 \%$ portion, the physical and mechanical properties of the wood plastics turned out to be significantly the best (i.e. reaching maximum values). 
3. From the three wood species selected for the manufacture of wood plastics and referring to the results of examining their anatomical features, tusam seemed to be the most permeable for its impregnation by aqueous solution of certain chemicals. This is because it has a relatively considerable portion of tracheid cells (as softwood) together with their numerously minute pits, thereby facilitating the movement of the chemicals inside its wood structure.

\section{B. Recommendations}

Modifying wood of particular species (i.e. into wood plastics, in this regard) through its impregnation using the styrene-vinyl, acetate monomers at certain respective mixed proportion could improve its physical and mechanical properties, in comparison to those of unmodified (unimpregnated) wood. However, the increase in styrene portion did not always brought about higher physical/mechanical properties of the resulting wood plastics. Therefore, it is strongly recommended that trial on the wood plastics manufacture deserve its continuation. In this regard, several manners can be tried, e.g. the use of monomers other than styrene, implementation of modified impregnation methods, the application of additives/catalysts which facilitate the appropriate curing of monomers into a more stable polymer chain/bonds.

\section{ACKNOWLEDGEMENT}

We would like to express our gratitude to Prof. Dr. Ir. Yusuf Sudo Hadi M.Agr. from Bogor Agricultural University for his generousity advising this research.

\section{REFERENCES}

; Allock, H.R. and F.M.M. Lampe. 1981. Contemporary Polymer Chemistry. Prentice Hall, Inc., New Jersey.

Cowd, M.A. 1991. Kimia Polimer. Institut Teknologi Bandung, Bandung

Moot, W.E. and G.J. Rotairu. 1968. Impregnation and polymerization method and system used in the production of wood-polymer materials in impregnated fibrous materials. Report of a Study Group Bangkok 20-2 November 1967. International Atomic Agency, Vienna.

Hadi. Y.S., H.S. Wuisang, N. Hadjib and M. Utama. 1998. Physical and mechanical properties of methyl metacrylate impregnated betung (Dendrocalamus asper). Introductory paper. Proceedings of Second International Wood Science Seminar. JSPS-LIPI Core University Program in The Field of Wood Science. Serpong, Indonesia.

Hadjib, N., Barly and Y.I. Mandang. 1998. Physical and mechanical properties of several oils impregnated on wood. Prosiding Seminar Nasional I, MAPEKI (Indonesian Wood Research Society). Bogor Agricultural University. 
Hadjib, N. and Abdurachman. 1999. The physical and mechanical properties of several wood species from West Java. Buletin Penelitian Hasil Hutan Vol. 16 (5).

Hadjib, N. and G. Sumarni. 2000. Wood modification improving the quality of wood. Prosiding diskusi peningkatan kualitas kayu. Badan Penelitian dan Pengembangan Kehutanan dan Perkebunan.Bogor. 
Appendix 1. Analysis of variance on the physical and mechanical properties of wood plastics tested

\begin{tabular}{|l|c|c|c|}
\hline \multirow{2}{*}{$\begin{array}{c}\text { Physical/ mechanical } \\
\text { properties }\end{array}$} & \multicolumn{2}{|c|}{ Mean squares of the sources of variation } \\
\cline { 2 - 4 } & $\begin{array}{c}\text { Wood species } \\
(2)^{1}\end{array}$ & $\begin{array}{c}\text { Treatment } \\
(4)\end{array}$ & $\begin{array}{c}\text { Error } \\
*(53)\end{array}$ \\
\hline - Moisture content & 144.87 & $1118.82^{* *}$ & 112.19 \\
\hline - Specific gravity/density & 0.39 & $0.47 * *$ & 0.01 \\
\hline - Volumetric shrinkage & $12.58 *$ & $17.37 * *$ & 2.25 \\
\hline - Volumetric swelling & 5.76 & $8.37 * *$ & 1.02 \\
\hline - Water absorption & 2869.59 & 4527.90 & 224.87 \\
\hline - MOE & 9960764449 & $2659074554 *$ & 832688277 \\
\hline - MOR & 2830215.23 & $472260.53 * *$ & 67214.41 \\
\hline - Compression // to grain & 357252.21 & $19319.01 *$ & 6745.81 \\
\hline - Hardness & 2316422.09 & $267793.36 * *$ & 19133.16 \\
\hline
\end{tabular}

Remarks: ${ }^{1)}$ Figures in parenthesis mean degrees of freedom

${ }^{2)}=$ Various mixed proportions between styrene and vinyl acetate monomers

* = significant at $5 \%$ level $(\mathrm{P}=0.95)$

$* *=$ significant at $1 \%$ level $(\mathrm{P}=0.99)$ 